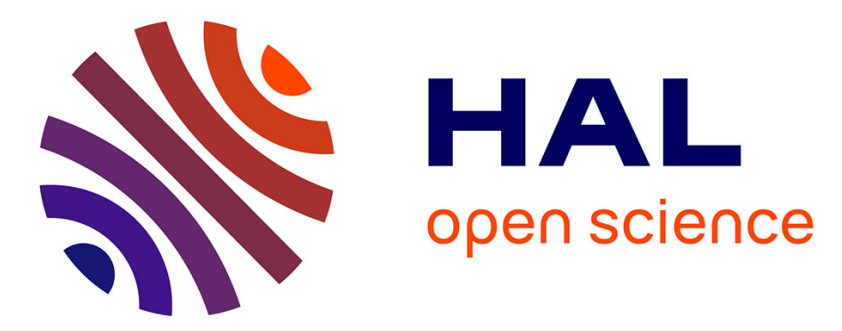

\title{
Towards a quantitative rationalization of multicomponent glass properties by means of Molecular Dynamics simulations
}

\author{
Maria Cristina Menziani, Gianluca Malavasi, Alfonso Pedone
}

\section{To cite this version:}

Maria Cristina Menziani, Gianluca Malavasi, Alfonso Pedone. Towards a quantitative rationalization of multicomponent glass properties by means of Molecular Dynamics simulations. Molecular Simulation, 2007, 32 (12-13), pp.1045-1055. 10.1080/08927020600932793 . hal-00515001

\author{
HAL Id: hal-00515001 \\ https://hal.science/hal-00515001
}

Submitted on 4 Sep 2010

HAL is a multi-disciplinary open access archive for the deposit and dissemination of scientific research documents, whether they are published or not. The documents may come from teaching and research institutions in France or abroad, or from public or private research centers.
L'archive ouverte pluridisciplinaire HAL, est destinée au dépôt et à la diffusion de documents scientifiques de niveau recherche, publiés ou non, émanant des établissements d'enseignement et de recherche français ou étrangers, des laboratoires publics ou privés. 


\section{Molecular Simulation}

Journal of

Experimental Nanoscience

- Taylor \& Francis

Taglor S Francis Group

\section{Towards a quantitative rationalization of multicomponent glass properties by means of Molecular Dynamics simulations}

\begin{tabular}{|r|l|}
\hline Journal: & Molecular Simulation/Journal of Experimental Nanoscience \\
\hline Manuscript ID: & GMOS-2006-0080.R1 \\
\hline Journal: & Molecular Simulation \\
\hline $\begin{array}{r}\text { Date Submitted by the } \\
\text { Author: }\end{array}$ & $14-J u l-2006$ \\
\hline Complete List of Authors: & $\begin{array}{l}\text { Menziani, Maria Cristina; University of Modena \& Reggio E., } \\
\text { Chemistry } \\
\text { Malavasi, Gianluca; University of Modena \&Reggio E., Chemistry } \\
\text { Pedone, Alfonso; University of Modena \&Reggio E., Chemistry }\end{array}$ \\
\hline Keywords: & Molecular Dynamics simulations, Multicomponent Glasses, QSPR \\
\hline
\end{tabular}

\section{SCHOLARONE ${ }^{m}$ Manuscripts}


Gianluca Malavasi, Alfonso Pedone, M.Cristina Menziani*

Department of Chemistry, University of Modena and Reggio Emilia, Via G.Campi 183, 41100 Modena, Italy.

gmalavasi@unimo.it, pedone.alfonso@unimo.it, menziani@unimo.it

Running head: MD study of glass properties

Keywords: Molecular Dynamics simulations, Multicomponent Glasses, QSPR

Corresponding author

Prof. Maria Cristina Menziani

Dipartimento. di Chimica,

Università degli Studi di Modena e Reggio Emilia

Via Campi 183

41100 Modena (Italy)

e-mail: menziani@unimo.it

Tel. +390592055091 Fax +39059373543 


\begin{abstract}
This review summarizes the achievements obtained by making use of Molecular Dynamics (MD) simulations in the elucidation of the structure of multicomponent glasses exerting bioactive properties. Emphasis on critical aspects of MD simulations for oxide glasses treatment is given. The potentiality of the quantitative structure-property relationships (QSPR) analysis as a tool for interpretative and predictive purposes is highlighted.
\end{abstract}




\section{Introduction}

A prerequisite for tailoring glass forming systems to meet predefined physical properties and ever-changing industrial needs is the correct understanding of their structure-property relationships.

Unfortunately, the elucidation of glass structures is still a difficult task. Not a single experimental technique is able to provide a sound structural model of amorphous systems even for chemically simple glasses, and the combination of many different experimental data, such as X-ray Absorption Fine Structure, Neutron Diffraction, Nuclear Magnetic Resonance, Infrared and Raman spectroscopy, has to be considered to collect different, complementary information. As a consequence, difficulties in data interpretation and apparent contradictory structural evidences have to be faced. To progress further in this field theoretical simulation is therefore critical.

In the last years a computational research activity devoted to support the experimental techniques, overcome and deepen the interpretative levels obtained from the experiments has been consolidated in the field.[1] In particular, molecular dynamics (MD) simulations provide atomic level pictures of the glass structures, deep understanding of composition-atomic structure relationships and insight into the reactivity of complex materials.[2] Recent advances in the interatomic potential energy functions allow the correct quantitative evaluation of the numerical value of structural, mechanical, thermo-physical, and transport properties for simple glasses.[3,4] However, accurate and reliable descriptions of the same properties for multicomponent glasses has proved far more difficult, although general trends that are consistent with experimental results can be obtained.

A breakthrough in material design will result from the enhancement of the predictive capability of MD simulations. Theoretical quantitative structure-property relationship (QSPR) analysis might constitute a valuable instrument for the optimization of the final properties of a 
set of chemical objects. It relates properties to numerical representations of structures through mathematical models, thus assuming an immense practical importance in the development of predictive and interpretative models.[5] This technique, commonly used in drug design, allows designers to develop better materials with a grater focus on end-user application requirements, reduce development costs and speed time to market. However, its application in the field of material design is only now being explored.[6]

We will restrict this review to our efforts in establishing sound relationships among the structural role of some key elements that appear to control the physicochemical properties of silicate and phospho-silicate glasses with potential bioactive properties.

The review is organized as follows: first the basic features of the structure of silicate glasses are summarized and the requirements for glass bioactivity are discussed. Then computational details for MD simulations are given with emphasis on critical points for oxide glasses treatment. Some important MD results that allow significant insight into glass structure at various scale length are then reviewed and compared with experimental data. Finally, the potentiality of QSPR analysis as a tool for interpretative and predictive purposes is highlighted.

\section{Factual information on glass structure}

There are still open questions on how the basic building blocks of one-component glasses such as $\mathrm{SiO}_{2}$ or $\mathrm{B}_{2} \mathrm{O}_{3}$ are organized to form the bulk of the vitreous material. Obviously, the situation is even more obscured in multi-component glasses. However, there is general agreement on the various scales of order: short-range order (1.5-2.9 $)$ concerns cationoxygen polyhedral units and obeys the same chemical rules as in crystals; medium-range

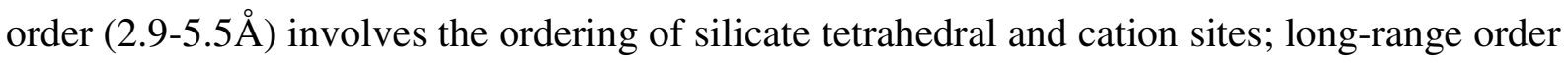

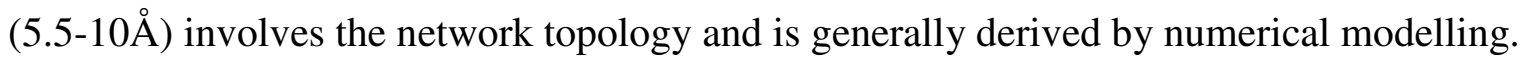


In the silicate glasses the $\mathrm{SiO}_{4}$ tetrahedra are connected at the corners to form a continuous three-dimensional network which constitutes the backbone of the structure. Rings of different sizes that occur in a wide range of geometries and conformations are formed. Alkali oxides reduce the degree of connectivity in the network breaking the Si-O-Si link and replacing bridging oxygens (BO) by non-bridging oxygens (NBO) bonded to only one silicon atom. The medium-range configuration around the silicon atoms is expressed as $Q^{n}$ ( $n=0$ to 4$)$, where $n$ is the number of BOs. Cations are usually classified as network formers, network modifiers, which interact with the bridging oxygens to depolymerise the network, or charge compensators for non tetravalent network forming elements.[7]

Many important macroscopic properties of silicate glasses, such as viscosity, glass transition temperature, or resistance to chemical change, for example via corrosion, are dramatically altered by changes in the composition.

\subsection{Bioactive glasses}

In the presence of body fluids, and depending upon the rate of ion release and resorption, bioglass and bioglass-ceramics [8] create chemical gradients which promote, early in the implantation period, the formation of a layer of biologically active bone-like apatite at the interface. Bone-producing cells, i.e. osteoblasts, can preferentially proliferate on the apatite, and differentiate to form new bone that bonds strongly to the implant surface.[8]

Solubility is, therefore, a prerequisite for bioactivity. Glass solubility increases as network connectivity is reduced. Consequently, bioactivity occurs only within certain compositional limits and very specific ratios of oxides in the $\mathrm{Na}_{2} \mathrm{O}-\mathrm{K}_{2} \mathrm{O}-\mathrm{CaO}-\mathrm{MgO}-\mathrm{B}_{2} \mathrm{O}_{3}-\mathrm{P}_{2} \mathrm{O}_{5}-\mathrm{SiO}_{2}$ systems.[9] The physico-chemical and biochemical reasons for these compositional limits and their extent and for the behaviour of additional ions that can tailor new important mechanical and biological properties for specific clinical applications [10] are poorly known at present. 
To throw same light in this field, we followed a rational MD simulation approach to the design of new potential bioglass compositions. The systems studied and discussed in this review are listed in Table 1 . Zinc has been added to the parent compositions $2 \mathrm{SiO}_{2} \cdot \mathrm{Na}_{2} \mathrm{O} \cdot \mathrm{CaO}$ [11] and (2-p) $\mathrm{SiO}_{2} \cdot 1.1 \mathrm{Na}_{2} \mathrm{O} \cdot \mathrm{CaO} \cdot \mathrm{pP}_{2} \mathrm{O}_{5}(\mathrm{p}=0.10)$ [10] since it improves chemical durability and mechanical properties of the glass.[12,13] Moreover, the slow release of zinc incorporated into an implant material promotes bone formation around the implant and accelerates recovery of the patient.[14]

\section{Computational details}

Many factors in the computational protocol adopted can influence the final structural model obtained. Force fields, cooling procedure and the simulation cell size used in MD calculations may have a considerable impact on the final atomic arrangement obtained. Hence, comparison with the experimental data is mandatory to provide conviction on the reliability of the structural model obtained.

\subsection{Force-fields}

The atomistic approach to model structure and other properties of materials involves the definition of inter-atomic potential functions to simulate the forces acting between atoms. The total potential energy is generally broken down into pair, three-body and higher order terms depending on the chemical-physical features of the system under study.

The interatomic pair potential can be written as:

$U_{i j}(r)=\frac{q_{i} q_{j} e^{2}}{r}+\varphi_{i j}(r)$

Where $q_{i}$ and $q_{j}$ are the ionic charges, $r$ the inter-atomic distance, $\varphi_{i j}$ are the short-range interactions which are attributed to the repulsion between electron clouds, van der Waals attraction, polarization effects and, when needed, bond terms.

For ionic or partially ionic materials the most commonly functional form for non-bonded potential is the Buckingham function. It is worth noting that when partial charges are assigned 
to ions the contribution of the dispersion term in the Buckingham function become important and the Buckingham potential assumes unphysical values at low inter-nuclear distances. This can be problematic when the temperature used in the simulation is high. Therefore, many authors add a repulsive term of the type $D / r^{n}$ to model quenching of melts and glass formation.[15,16,17]

In earlier structural studies we used a formal charge potential model developed by Vessal et al. [18] including a three-body term for the O-Si-O interaction. No constraints were explicitly considered for the $\mathrm{O}-\mathrm{Zn}-\mathrm{O}$ and $\mathrm{O}-\mathrm{P}-\mathrm{O}$ linkages in order to avoid assumptions on the coordination number of these cations. The parameters used are listed in Table 2.[19,20]

The choice of charges is not trivial. Due to the partial covalent properties of the silicate glasses, formal charges equated to the oxidation state are not realistic; the binding energy of the systems results overestimated and very high melting temperatures are needed.

In order to obtain a reliable description both of the structural and mechanical properties of oxides, silicate crystal and silica based glasses we recently developed a new pair-wise interatomic potential $[4,21]$ based on a rigid ionic model with partial charges to handle the covalent character of silicate systems. The potential is given by the sum of three terms: longrange forces are represented by a Coulombic potential, short-range forces are represented by a Morse function and repulsive contribution at high-temperature and pressure are modelled by the $C / r^{12}$ term:

$U_{i j}(r)=\frac{z_{i} z_{j} e^{2}}{r}+D_{i j}\left\{\left[1-\exp \left(-a_{i j}\left(r-r_{i j}\right)\right)\right]^{2}-1\right\}+\frac{C_{i j}}{r^{12}}$

where, $\mathrm{z}_{\mathrm{i}}$ is the charge of the $i$-th atom, $D_{i j}, a_{i, j} r_{i j}$ and $C_{i j}$ are parameters derived by empirical fitting (see Table 3). [4]

A step further into the prediction of dielectric, optical and medium range structural and dynamical properties is obtained by the inclusion of ionic polarizability.[3] 


\subsection{Cooling procedure.}

Bulk glasses are usually made via a simulated melt-quench technique, in which a system of atoms is either a crystalline structure or a random distribution into a central periodically repeated cell. To compensate for faulty assumption of periodicity large unit cells, comprising thousands of atoms are needed. The system is brought to high temperature for tens of picoseconds in order to generate a simulated melt with no memory of the initial atom configuration. The melting temperature strictly depends upon the characteristics of the potentials used, namely the values of the charges employed. Cooling of the melt can occur via several protocols based on lowering the temperature continuously or by large steps in which the system undergoes an instantaneous decrement followed by a relaxation period. The statistical ensemble (NVE, NVT or NPT) is also an element of choice. The structures generated are sensitive to the temperatures and times used in the simulation procedure; therefore much attention has been paid on this matter in the literature.[22,23,24,25]

Different cooling procedures have been adopted in our studies according to the set of potentials used and in the attempt to optimize simultaneously accuracy of the results obtained and computational efficiency.

Procedure I: This procedure is suited for MD simulations employing full ionic charge potentials. The starting volume of the system is increased up to $30 \%$ to account for the estimated thermal expansion and then scaled to reproduce the experimental density at the final simulation temperature during the quenching procedure. The initial structure is melted at $12000 \mathrm{~K}$ and then cooled down sequentially to 10000 , 8000, $6000,3000,1500$, and finally to $300 \mathrm{~K}$, using a quench rate of $4 \times 10^{13} \mathrm{~K} / \mathrm{s}$.[26]

At each temperature a 20000 time steps relaxation is allowed. During the first 6000 of these 20000 time steps, the velocity is scaled every time step. During the second 6000 time step, velocity scaling every 40 time steps is performed, and finally, during the last 8000 time steps, 
no velocity scaling is applied. The canonical ensemble NVT (Evans thermostat) [27] is used in order to maintain the experimental density of the system during the simulation procedure. Data collection is performed every 50 time steps during the last 10000 of 35000 time steps using the micro-canonical ensemble NVE. Coulomb interactions are calculated by the Ewald summation method with a cut-offs of $12 \AA$ and a precision of $10^{-4}$ and the short range interaction cut-off is set to $7.6 \AA$. The accuracy and reliability of the quenching protocol was judged comparing structural features obtained by means of molecular simulations with those experimentally determined.[26]

Procedure II: This procedure is suited for MD simulations employing partial ionic charges $(\mathrm{qO}=-1.2 \mathrm{e})$ potential. Using the constant volume NVT simulation with Evans algorithm, the system is cooled down from 5000 to $300 \mathrm{~K}$, decreasing the temperature with steps of $500 \mathrm{~K}$. The nominal cooling rate is $1 \times 10^{13} \mathrm{~K} / \mathrm{s}$.[17] Cut offs are set to $8.0 \AA$ and $5.5 \AA$ for the Coulomb and short range interactions, respectively.

In both cases, integration of the equation of motion is performed using the Verlet Leap-Frog algorithm with a time step of 2 fs. MD simulations are performed on samples of 1500 or 3000 atoms by means of the DL_POLY ${ }^{\circledR}$ package.[28,29]

Open source codes devoted to the analysis of MD results and identification of structural properties such as total distribution functions, pair and radial distribution functions, bond angle, Qn, void size [17] and clusters distribution [30] have been developed in our lab (see Figure 1) and are available at the http://www.ccp5.ac.uk/librar.shtml site.

\section{Insight into glass structure from MD simulations}

\subsection{Coordination geometries}

The $\mathrm{Zn}^{2+}$ ion is known to present two common coordination geometries in oxygenated species: tetrahedral and octahedral. According to the Zachariasen and Warren theory of 
glass,[7] $\mathrm{Zn}^{2+}$ is therefore classified as an intermediate species, the tetrahedral coordination being typical of glass network formers and the octahedral one of modifiers. Preferences in the geometry adopted are dictated by environmental factors, and, in particular, by the amount of alkali oxides in the glass.[31,32,33]

A pioneer MD simulations study carried out by Rosenthal and S.H. Garofalini $[34,35]$ on binary and ternary silicate glasses with high alkali oxide concentrations highlighted a tetrahedral preference in the coordination of the zinc ions, in perfect agreement with the results of extended x-ray absorption fine structure (EXAFS) studies carried out on glasses of the same compositions and on crystalline zinc silicates. These results affirmed MD simulations to be a powerful tool for deciphering the local features around individual ions and helping the understanding of glass properties.

Confident in the assumption that reasonable rationalization of the glass structure can be derived from the analysis of compositionally equivalent crystalline phases,[36] we approached the study of the structural features of the multicomponent zinc containing bioglasses combining the information derived by MD simulations with those derived from the analysis of the crystal phases isolated from the glasses by controlled crystallization.[12,13,30,37,38]

A clear preference of the zinc ions to occupy four-fold sites over all the compositional range considered is observed in the KZ, KSZ, HZ, HP5Z, and HP6.5Z glass series. [12,13,30,37] The main contribution to the zinc ion coordination is ascribed to the BO species, implying its network former structural role in these glasses. $\mathrm{Zn}$ addition progressively reduces the high number of the Si-NBO species characteristic of the soda-lime glasses, thus contributing to network polymerization. However, the $\mathrm{Zn}$ tetrahedra have longer average cation-oxygen distances with respect to $\mathrm{Si}$ and the internal bonding is weaker with respect to the surrounding silicate tetrahedra. 
In Figure 2 the short range order of the $\mathrm{KZ} \mathrm{x}=0.68$ glass (Figure 2(a)) is compared with the

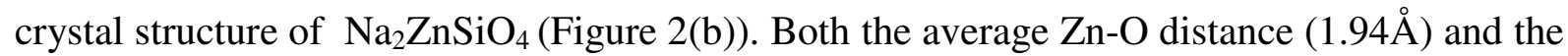
Si-O-Zn bond angle $\left(131^{\circ}\right)$ determined by MD simulations compare well with the values found for the crystal phase $\mathrm{Na}_{2} \mathrm{ZnSiO}_{4}$, which are $1.95 \AA$ and $128^{\circ}$, respectively. Substitution of $\mathrm{ZnO}$ for $\mathrm{Na}_{2} \mathrm{O}$ in $\mathrm{KNZ}$ glasses leads to the ternary glass $\mathrm{CaO} \cdot 2 \mathrm{SiO}_{2} \cdot \mathrm{ZnO}$. The zinc ions are found copolymerised with the silicate network in tetrahedral sites progressively more distorted as $\mathrm{Na}$ depletion takes place. A significant percentage of 3-fold $\mathrm{Zn}$ ions is, in fact, observed in the $\mathrm{CaO} \cdot 2 \mathrm{SiO}_{2} \cdot \mathrm{ZnO}(\mathrm{KNZ} \mathrm{z}=1.00)$ glass, yielding an average coordination number of 3.6. Disorder in the structures is contributed by the presence of triclusters (TBO), i.e. oxygen atoms bonded to three ion formers. TBO species are mainly associated with zinc and are characteristic of willemite, a phase separated upon crystallization of the $\mathrm{CaO} \cdot 2 \mathrm{SiO}_{2} \cdot \mathrm{ZnO}$ glass.[39]

Phosphorus manifests a preference for the 4-fold coordination in the HZ, HP5Z and HP6.5Z glass series, but does not participate in the network. In fact, being surrounded preferentially by NBO it forms isolated tetrahedra. Only high concentrations of zinc ions ( $\mathrm{HZ} \mathrm{x}=0.32,0.78$; HP5Z $\mathrm{x}=0.36,0.96 ; \mathrm{HP} 6.5 \mathrm{Z} \mathrm{x}=0.36,0.58)$ force $\mathrm{P}$ to form a significant percentage of linkages (BO and TBO) with others network former ( $\mathrm{Si}$ and $\mathrm{Zn}$ ).[13] A similar behaviour is observed in phospho-silicate glasses added with $\mathrm{Al}_{2} \mathrm{O}_{3} \cdot[40]$

The anisotropy of the tetrahedrally hybridized $\mathrm{P}$ orbitals constitutes a serious challenge to model phosphate chemistry with reliable empirical force fields. A test of the reliability of the parameterization used in our MD study for the $\mathrm{P}$ atom is provided by the comparison of the short-range structure observed from the simulation with the one experimentally determined. Distances, angles and coordination numbers of the $\beta-\mathrm{NaCaPO}_{4}$ phase obtained from crystallization of the glasses under study are compared with the values obtained from the simulations, as shown in Figure 2 (c) and (d). 
Local geometry is reproduced reasonably well, the apparent discrepancy in the average P-O distance ( $1.51 \AA$ found by MD simulation vs. $1.54 \AA$ observed in the $\beta-\mathrm{NaCaPO}_{4}$ crystal) is resolved by considering that the mean values are averaged over a range of distances spanning $1.48-1.61 \AA$ in the crystal, whereas the full width at half height of the P-O peak in the simulated pair distribution function is $1.44-1.55 \AA$. Therefore, while it is likely that a more accurate parameterization would be necessary in order to reproduce experimental thermodynamics parameters and second order properties, a simple forcefield, which includes only the two-bonded interaction terms and formal charges, seems to be sufficiently adequate to derive structural descriptors.

\subsection{From short to medium-range order}

\subsubsection{Cation clustering}

According to the modified random network model of glass structure,[41] the alkali ions are not uniformly distributed through the silica cage but rather are clustered inhomogeneously forming alkali-rich regions and silica-rich regions. The scenario depicted by this qualitative model is quantitatively confirmed and extended by the results of MD simulations on the complex multicomponent glasses studied in our lab.

The analysis of the medium-scale structure as a function of glass composition reveals a clear tendency of the constituting cations to segregate in the network.[12,13,30, 37,38,39] Thus, the progressive addition of zinc oxide to the parent glasses studied causes an overall decrease of NBO species and a total rearrangement of the glass structure; segregation zones for the Ca ions are observed in close proximity to Si-NBO and P-NBO species; the Na ions, almost uniformly distributed, assume different structural roles behaving as modifiers in close proximity of $\mathrm{Si}$ tetrahedra, and as charge compensators in proximity of $\mathrm{Zn}$ tetrahedra. Similar phenomena have been observed in sodium zinc silicate glasses,[34,35] soda-lime [42] and sodium aluminosilicate glasses.[43] In the Na-depleted glass (KNZ series) balancing of the zinc tetrahedra 
charges is achieved in several ways such as competition with $\mathrm{Si}$ ions to attract $\mathrm{Ca}$ as chargecompensating cations, formation of triclusters, and, in the absence of $\mathrm{Na}$, distorsion of the tetrahedral geometry up to a tri-coordinated pyramidal geometry. This picture of the glass structure is in full agreement with the crystal phases identified after glass crystallization, which shows that the zinc atoms are embedded in calcium-rich regions only when there is shortage of $\mathrm{Na}$ ions or in the Na-free glass.[39]

By increasing the concentration of phoshorous, the randomly disseminated monophosphate $\left(Q^{0} \mathrm{P}\right)$ units found in the parent HP glass tend to gather together in islets characterized by the presence of $\mathrm{P}, \mathrm{Na}$ and $\mathrm{Ca}$ ions. High concentration of zinc in the glasses promotes the participation of $\mathrm{P}$ to the glass network by forming a highly ramified backbone of interconnected Si-Zn-P tetrahedral. Finally, pairs of corner sharing $\mathrm{ZnO}_{4}$ tetrahedra are formed giving rise to zinc-rich regions, where long strips of $\left[\left(\mathrm{ZnO}_{4}\right)_{n}-\left(\mathrm{SiO}_{4}\right)_{N}\right]_{m}$ tetrahedra surrounded by $\mathrm{Na}$ ions are found.

\subsubsection{Prediction of crystal phases}

If the phenomenon of micro-segregation in multicomponent glasses can be considered a preorganization step for crystal nucleation, then it is possible to validate the computational models by comparing the medium-scale organization of the atoms in the MD simulation box with the one found in the crystalline phases obtained by controlled crystallization.[30] More importantly, it is also possible to predict, from MD simulations, the most probable crystal phases that could separate from glasses. This is a very interesting point, since an exact theory for the prediction of the specific crystalline phases that a ionic mixture could form on the basis of its chemical composition is, as yet, not available. However, such a predictive tool could have outstanding consequences for the engineering of new composite materials with improved mechanical and biological properties with respect to the parent glass since the 
chemical composition, the content of the crystals and morphology of the glass-ceramics are the important factors that determine the properties of the materials.

Recent results from extended X-ray absorption fine spectroscopy and ${ }^{29}$ Si MAS-NMR studies support the hypothesis that crystal nucleation can take place relatively easily in the glass volume provided that the local structure of a glass and its isochemical crystal are similar.[44,45]

On this basis, we have developed a program (named CLUSTER) able to sample systematically the ratios of the ions in different portions of the simulation box and compare them with the stoichiometric ratio of a number of compositionally-equivalent crystalline solids stored in the Inorganic Crystal Structure Database (ICSD), NIST, database.[46]

To facilitate the quantitative analysis a similarity index has been elaborate based on the Hamming distance $(\Delta(r))$ between the two ionic ratios:

$$
\Delta(r)=\sum_{j=1}^{n}\left|\chi_{j A}-R_{j A}\right|
$$

where, the elements of the vector $\mathbf{R}_{A}$ are the stoichiometric coefficients of the crystal phase $A$, the vector $\chi_{A}$ contains the minimal ratios for the ions lying inside the sphere of radius $r$, and $n$ represent the order of the vectors. $\Delta(r)$ ranges from 0 to $\infty$; for $\Delta(r)=0$ the exact stoichiometry of the $A$ crystal phase is found.

The crystal phases obtained by thermal treatment of the glasses under study has definitely demonstrated the predictive power of the similarity index elaborated.[30] The results are summarized in Table 4, where the $\bar{\Delta}(\boldsymbol{r})$ data values, which represent the average of $\Delta(r)$ over the ten values of the radius of the sphere analyzed, are listed together with the crystal phases and relative intensities $\left(\mathrm{I} / \mathrm{I}_{0}\right)$ of the principal peaks identified by XRD analysis of the glasses. All the main crystal phases, showing a $\bar{\Delta}(\boldsymbol{r})$ data values less than 1 , are well predicted.

\subsubsection{Insight from spectroscopic analysis}


The synergistic application of MD simulations and NMR and Raman analytical techniques showed to provide valuable insights into the structural features responsible for the macroscopic behavior of glasses.[13,39,43]

\subsubsection{MAS-NMR}

One of the most valuable information that can be obtained from magic angle spinning (MAS) NMR is the quantitative determination of $\mathrm{Q}^{\mathrm{n}}$ units distribution in the amorphous system.[47] Unfortunately, the Q-resolution capacity of NMR is limited by the fitting of heavily overlapping NMR spectra, which required an assumption of a Gaussian distribution in NMR parameters. This is a common practice in solid-state NMR analyses of glasses, but there is no justification for this other than the central limit theorem. Additionally, such analyses are forced to assume specific (typically random) correlations between NMR parameters.[48]

In general, for the type of lineshapes observed in multicomponent glasses the use of deconvolution techniques for extracting peak intensities from overlapping spectra may not lead to a unique solution.

In our approach, precious information on the connectivities between different types of $\mathrm{Q}^{\mathrm{n}}$ species derived by MD simulations has been used as additional constraints to verify the found solutions from ${ }^{31} \mathrm{P}$ and ${ }^{29} \mathrm{Si}$ (MAS) NMR deconvolution. [30,43]

For example, the ${ }^{29} \mathrm{Si}$ MAS-NMR spectrum of the zinc free HZ sample can be deconvolved into two peaks centered at -80 and $-87 \mathrm{ppm}$, assigned to $Q^{2}$ and $Q^{3}$ silicon structural units, respectively.[30,49] The addition of $\mathrm{ZnO}$ to the silica matrix determines a shift of the centre of mass of the ${ }^{29} \mathrm{Si}$ MAS-NMR spectrum toward the paramagnetic direction (downfield). Rather than calling for a general progressive depolymerization of the silica network $\left(Q^{n} \rightarrow\right.$ $\left.Q^{n-1}\right)$, the results of MD simulations advocate the establishment of new Si-O-Zn structural units $\left[Q^{n}(\mathrm{Zn})\right]$. Besides, a simple electrostatic model [50] shows that the substitution of a zinc ion for a silicon ion in a $Q^{n}$ unit causes the chemical shift to decrease of about $10 \%$, in 
agreement with the tentative spectra assignments for the $\mathrm{HZ} \mathrm{x}=0.32$ and 0.78 glasses. In this framework, apparent contradictions in the trends observed between the NMR Q-speciation and the amount of zinc added to the glasses can be rationalized by invoking the formation of structural units of the type $Q^{3}(2 \mathrm{Zn})$, in which the central silicon is linked to one $\mathrm{SiO}_{4}$ and two $\mathrm{ZnO}_{4}$ tetrahedra. These units, characterized by a chemical shift very close to that of the $Q^{2}(\mathrm{Zn})$ groups, in which the central silicon is linked to one $\mathrm{ZnO}_{4}$ and one $\mathrm{SiO} 4$ tetrahedra, are indeed found in the structural models obtained by MD simulations. [13]

The ${ }^{31} \mathrm{P}$ MAS NMR spectra of the same HZ samples show a main peak at about $8 \mathrm{ppm}$, attributed to monophosphate $\left(Q^{0}\right)$ units;[49] zinc addition causes the progressive increase of a shoulder at $\sim 2 \mathrm{ppm}$, assigned to $Q^{l}$ units. The resulted $\mathrm{P}$ average $Q^{n}$ is in perfect agreement with the one derived by MD simulations, which ranges from 0.5 in the $\mathrm{Zn}$-free glass to 1.78 in the $\mathrm{HZ}(\mathrm{x}=0.78)$, associated to the progressive establishment of highly ramified backbone of interconnected Si-Zn-P tetrahedral.

\subsubsection{Raman}

The intensity and the frequency of the Raman lines depend on the concentration of the alkali and alkali-earth oxides in the glasses,[51] therefore we expected to gain a better knowledge of the structural role of the network modifiers in the KNZ series of glasses, where complete substitution of $\mathrm{ZnO}$ for $\mathrm{Na}_{2} \mathrm{O}$ in the starting composition $\mathrm{Na}_{2} \mathrm{O} \cdot \mathrm{CaO} \cdot 2 \mathrm{SiO}_{2}$ is achieved.[39] Despite being the silica based glasses extensively studied, the interpretation of the vibrational spectra is generally qualitative, and, significant discrepancies on the assignment and nomenclature of the spectral lines in alkali or alkaline earth silicate glasses are observed in the literature. Therefore, also in this case, a combined Raman/MD approach proved to be useful. The Raman spectra of glasses containing low zinc concentrations $(\mathrm{KZ} \mathrm{x}=0$ and $\mathrm{KNZ} \mathrm{x}=0.20)$ manifest two signals at about 1030, and $970 \mathrm{~cm}^{-1}$ attributed to the Si-NBO stretching vibrations in $\mathrm{Q}_{\mathrm{Si}}{ }^{2}$ and $\mathrm{Q}_{\mathrm{Si}}{ }^{3}$ silicon tetrahedral units, respectively. In the zinc-rich glasses 
$(\mathrm{KNZ} \mathrm{x}=0.60$ and $\mathrm{KNZ} \mathrm{x}=1.00)$ the two bands gradually merge. A rational for this behaviour can be found in the structural model obtained for these glasses by MD simulations: the number of structural units containing $\left.\mathrm{QS}_{\mathrm{Si}}{ }^{2} \mathrm{Na}\right)$ or $\left.\mathrm{Q}_{\mathrm{Si}}{ }^{2} \mathrm{Ca}\right)$ species diminishes as a function of zinc concentration to favour the formation of Si-O-Zn bridges yielding $\left.\mathrm{Q}_{\mathrm{Si}}{ }^{3} \mathrm{Zn}\right)$ units.

\section{Quantitative Structure-Property Relationship (QSPR) analysis.}

A very useful tool to gain "rational" control of the structure of complex real-life systems at all relevant length scales is the quantitative structure-property relationship (QSPR) approach. This approach makes use of mathematical functions to relate observable properties of materials to their intrinsic molecular structure. Thus, a deeper understanding of the structural features important for a particular observed property of the material in its "working" environment is achieved and the design of innovative materials with specific structures, properties and composition is facilitated.

The formulation of informative QSPR models adequate for multicomponent disordered systems is anything but trivial. We have attempted the first studies in this field by relating, in a quantitative way, theoretical structural descriptors derived from MD simulations to the variation of experimental data such as density, thermal properties, ${ }^{29} \mathrm{Si}$ and ${ }^{31} \mathrm{P}$ MAS NMR spectra, gas solubility, and chemical durability.[13,52]

\subsection{Theoretical structural descriptors}

The ability to obtain good quantitative rationalization of important material properties depends primarily on the information content of the descriptors utilized. To this regard, MD simulations can provide a plethora of promptly available descriptors among which to select the most informative ones in relation to the statistical model (simple or multilinear regression) of choice and to the interpretation of the properties of interest. 
Simple descriptors such as average bond lengths, bond angles, coordination numbers, percentage of $\mathrm{NBO}$ or $\mathrm{BO}$ attached to different cations, etc... can be derived promptly from simple statistical averaging or from radial and pair distribution functions and their deconvolution, once the appropriate cut-off distances are defined. Others descriptors can be defined as a combination of these ingredients. For example, an overall descriptor of the degree of polymerization of the glass network can be represented by the total number of $\mathrm{X}-\mathrm{O}-\mathrm{X}$ bridges ( $\mathrm{X}$ represents network-forming cations) found in the simulated glasses; to compare different glass compositions this descriptor can be normalized for the total number of oxygen atoms in the simulation box $\left(N^{\circ} \mathrm{X}-\mathrm{O}-\mathrm{X} / \mathrm{O}_{\mathrm{tot}}\right)$. The overall strength of the network can be encoded into a descriptor by summing the X-O bond energy multiplied by the number of $\mathrm{X}-\mathrm{O}$ bonds in each bridge type.[13,52] Finally, useful descriptors of the mid-range structure of the glasses are derived from the Qn species, ring size distribution and void size distribution.[53] In particular, the interstitial volume (or free volume) is useful for the rationalization of many thermodynamic properties, such as solubility,[54,55] diffusion-related properties and transition range behaviour of glasses.[53]

Recently, we have developed a new algorithm to study the free volume distribution and the connectivity of holes in amorphous solids.[17] This is based on the Voronoi-Delaunay approach applied to systems of non uniform spheres. The algorithm has been tested by comparing the solubility of noble gasses into silica glass with the available experimental data and allowed for speculations concerning correlation between void size distribution and ring size distribution.

\subsection{QSPR models}


Statistical models can be obtained by making use of the structural descriptors derived and available experimental data. Among the examples reported in the literature $[13,52]$ we focus here on three cases instrumental to demonstrate the importance of this approach in: a) gaining insight into the physical processes determining the properties of interest (interpretation); b) predicting missing data, the prediction accuracy depending on the statistical robustness of the models; c) assisting in experimental data rationalization.

\subsubsection{Interpretative models}

$\mathrm{Zn}$ addition to phospho-silicate glasses increases the glass durability by diminishing the total concentration of ions leached by up to one order of magnitude, with respect to the parent $\mathrm{HZ}$ glass. A good interpretative model of the role of network polymerization on water chemical durability is obtained by the relationship between the total leaching $\left(\Sigma \% \mathrm{X}_{\mathrm{i}}\right.$, sum of $\%$ leaching of each constituent of the glasses) and the $N^{\circ} \mathrm{X}-\mathrm{O}-\mathrm{X} / \mathrm{O}_{\text {tot }}$ descriptor (Figure 3 (a)).[52] This suggests that solubility is hindered by the zinc tendency to copolymerize with the Si tetrahedral, manifested by a significant increasing of the total number of $\mathrm{X}-\mathrm{O}-\mathrm{X}$ bridges detected in the glass. This model explains the slow rate of zinc dissolution into the media and provides insights into the overall reaction rate reduction of the zinc-containing glasses, regulated by the progressive reduction of the number of NBO species which ensure the presence of large channels for alkali migration in the network and rapid exchange of $\mathrm{Na}^{+}$with $\mathrm{H}_{3} \mathrm{O}^{+}$at the glass surface.

\subsubsection{Predictive models}

The same descriptor $N^{\circ} \mathrm{X}-\mathrm{O}-\mathrm{X} / \mathrm{O}_{\text {tot }}$ showed to be able to explain the variation in the experimental density of a large number of glasses (Figure 3 (b)).[52] The positive slope indicates that density increases with the overall packing of the atoms in the glasses obtained by adding $\mathrm{Zn}$ or substituting $\mathrm{P}$ for $\mathrm{Si}$. It is worth noting that this descriptor allows different series of glasses (KZ, HZ, HP5Z and HP6.5Z) to be fitted in the same correlation. Moreover, 
the soundness of this model $\left(\mathrm{R}^{2}=0.987\right)$ is confirmed by its ability to predict the density values of the two glasses (test set: $\mathrm{TG} 1\left(\mathrm{SiO}_{2} 50.6, \mathrm{CaO} 42.5\right.$ and $\mathrm{ZnO} 6.9 \%$ in mol) and $\mathrm{TG} 2$ $\left(\mathrm{SiO}_{2} 48.6, \mathrm{CaO} 31.7\right.$ and $\mathrm{ZnO} 19.7 \%$ in mol)) with composition significantly different from the ones constituting the training set. This result affirms the importance of such an approach for predictive purposes and demonstrates the advantages offered with respect to the mathematical expressions available in literature and generally used to predict several composition-dependent properties. In fact, they consist in linear expressions, derived empirically or semi-empirically by assuming the additivity of the properties and one network former cation (mainly $\mathrm{Si}$ ), thus limiting their validity within a narrow range of concentration and compositions.[56]

\subsubsection{Assisting models}

The ${ }^{29} \mathrm{Si}$ MAS NMR spectra detects significant structural modifications in the simulated glasses upon $\mathrm{Zn}$ and $\mathrm{P}$ addition, and, within the approximation of the deconvolution scheme adopted, it is possible translate this information into a percentage of $\mathrm{BO}$ species that can be compared to the one obtained from MD simulation. A good correlation is, in fact, observed between the experimental $\%$ of $\mathrm{BO}$ and the number of Si-O-X bridges $\left(N^{\circ}{ }_{\text {Si-O-X }} / \mathrm{O}_{\text {tot }}\right)$ found in the simulated glasses $\left(\mathrm{BO}(\mathrm{NMR})=77.66 \mathrm{~N}_{\text {Si-O-X }}^{\circ} / \mathrm{O}_{\text {tot }}+29 ; \mathrm{n}=6, \mathrm{r}^{2}=0.947, \mathrm{~s}^{2}=3\right)$.

An estimation of the $\%$ of $\mathrm{BO}$ in the glass could be obtained merely from the glass compositional formula, but assumptions based on a preconceived notion of the glass structure are needed.[57] Thus, by assuming that $\mathrm{Si}$ and $\mathrm{P}$ play a traditional role in the glass, the $\%$ of BO computed for $\mathrm{H}$ and HP5 are 48.2 and 47.6, respectively. Moreover, by assuming a network former role for the zinc ion 54.5, 61.2, 75.5, and 53.9 are the $\%$ of BO obtained for HZ5, HZ10, HZ20, and HP5Z5, respectively, whereas 47.1, 45.8, 43.2, and 46.6 are obtained by assuming a modifier role for the zinc ions. The discrepancy observed in the values 


\section{Conclusions}

The main goal of computational material design is the optimization and prediction of specific properties which fulfil end-user application requirements. Thus, in the near future this technique will advance experiments, and accelerate the pace of technological advancement. Such an ambitious task requires the development of improved atomistic simulation methods that will enable the simulations of properties besides structure. For the time being, combination of computational simulations and QSPR analysis help to gain valuable information for the understanding of materials and chemical processes and furnishes a useful tool for predictive purposes. 


\section{References}

[1] S.H. Garofalini. Molecular Dynamics Simulations of Glass Surfaces and Interfaces. In Reviews in Mineralogy and Geochemistry, Cygan, T.T, Kubicki, J. D. Editors, pp 131-164, Geochemical Society \& Mineralogical Society of America, Washington DC (2001).

[2] A.N. Cormack, Y. Cao. Molecular Dynamics Simulation of Silicate Glasses. Molecular Engineering, 6, 183 (1996).

[3] A. Tilocca, N.H. de Leeuw and A.N. Cormack. Shell-model molecular dynamics calculations of modified silicate glasses. Phys. Rev. B, 73, 104209 (2006).

[4] A. Pedone, G. Malavasi, M.C. Menziani, A.N. Cormack and U. Segre. A New SelfConsistent Empirical Inter-Atomic Potential Model for Oxides, Silicates and Silica Based Glasses. J. Phys. Chem B, 110, 11780 (2006).

[5] A.R. Katritzky, U. Maran, V.S. Lobanov and M.Karelson. Structurally Diverse Quantitative Structure-Property Relationship Correlations of Technologically Relevant Physical Properties. J. Chem. Inf. Comput. Sci., 40, 1 (2000).

[6] M.E. Eberhart, D.P. Clougherty. Looking for design in material design. Nature Materials, 3,859 (2004).

[7] J.S. Shelby. Introduction to glass and technology. The Royal Society of Chemistry, Cambridge, UK (1997).

[8] T. Kokubo, An introduction to bioceramics. In Advanced Series in Ceramics. L.L. Hench, J. Wilson (Ed.)., World Scientific Publishing Co., Singapore (1993). Vol.1.

[9] M. Brink, T. Turunen, R.P. Happonen, A. Yli-Urpo. Compositional dependence of bioactivity of glasses in the system $\mathrm{Na}_{2} \mathrm{O}-\mathrm{K}_{2} \mathrm{O}-\mathrm{MgO}-\mathrm{CaO}-\mathrm{B}_{2} \mathrm{O}_{3}-\mathrm{P}_{2} \mathrm{O}_{5}-\mathrm{SiO}_{2}$. J. Biomed. Mater Res., 37(1), 114 (1997).

[10] L.L. Hench. Bioceramics. J. Am. Ceram. Soc., 81(7), 1705 (1998). 
[11] H.M. Kim, F. Miyaji, T. kokubo, C. Ohtsuki, T. Nakamura. Bioactivity of Na2O-CaOSiO2 glass. J. Am. Ceram. Soc., 78 (9), 2405 (1995).

[12] G. Lusvardi, G. Malavasi, L. Menabue, M.C. Menziani. Synthesis, characterization and molecular simulation of Na2O-CaO-SiO2-ZnO glasses. J. Phys. Chem. B, 106, 9753 (2002).

[13] L. Linati, G. Lusvardi, G. Malavasi, L. Menabue, M.C. Menziani, P. Mustarelli, U. Segre. Qualitative and Quantitative Structure-Property Analysis of Multicomponent Potential Bioglasses. J. Phys. Chem. B, 109, 4989 (2005).

[14] A. Ito, H. Kawamura, M. Otsuka, M. Ikeuchi, H. Ohgushi, K. Ishikawa, K. Onuma, N. Kanzaki, Y. Sogo, N. Ichinose, Zinc-releasing calcium phosphate for stimulating bone formation. Materials Science and Engineering: C, 22, 21 (2002).

[15] V.A. Bakaev, W.A. Steele. On the computer simulation of a hydrophobic vitreous silica surface. J. Chem. Phys. 111, 9803 (1999).

[16] J. Du, A.N. Cormack. The Medium Range Structure of Sodium Silicate Glasses: A Molecular Dynamics Simulation. J. Non-Cryst. Solids, 349, 66 (2004).

[17] G. Malavasi, M.C. Menziani, A. Pedone, U. Segre. Void size distribution in MDmodelled silica glass structures. J. Non-Cryst. Solids, 352, 285 (2006).

[18] B. Vessal, M. Amini, C.R.A. Catlow. Computer simulation of the structure of silica glass. J. Non-Cryst. Solids, 159, 184 (1993) and references therein.

[19] G.V. Lewis, C.R.A. Catlow. Potential model for ionic oxides. J. Phys. C: Solid State Phys., 18, 1149 (1985).

[20] J. Sauer, K.P. Schroder, V. Termath. Comparing the Acidities of Microporous Aluminosilicate and Silico-Aluminophosphate catalysts: A Combined Quantum MechanicsInteratomic Potential Function Study. Collect. Czech. Chem. Commun., 63, 1394 (1998).

[21] A. Pedone, A.N. Cormack, G. Malavasi, M.C. Menziani and U. Segre. In preparation. 
[22] E. Chagarov, J.B. Adams, J. Kieffer. Application of design of experiments methodology to optimization of classical molecular dynamics generation of amorphous $\mathrm{SiO}_{2}$ structure. Modelling Simul. Mater. Sci. Eng., 12, 337 (2004).

[23] N.T. Huff, E. Demiralp, T. Cagin, W.A. Goddard III. Factors affecting molecular dynamics simulated vitreous silica structures. J. Non-Cryst. Solids, 253, 133 (1999).

[24] K. Vollmayr, W. Kob, K. Binder. Cooling-rate effects in amorphous silica: A computersimulation study. Phys. Rev. B, 54, 15808 (1996).

[25] L.R. Corrales, J. Du. Thermal kinetics of glass simulations. J. Phys. Chem. Glasses. 46(4), 420 (2005).

[26] M.. Montorsi, C. Leonelli, M.C. Menziani, J. Du, A.N. Cormack. Molecular dynamics study of zirconia containing glasses. Phys. Chem. Glasses, 43(3), 137 (2002).

[27] D..J. Evans, G.P. Morris. Non-Newtonian molecular dynamics. Computer Physics Reports, 1, 297 (1984).

[28] W. Smith, T.R. Forester. http://www.dl.ac.uk/TCSC/Software/DL_POLY, 2000.

[29] W. Smith, T.R. Forester. DL_POLY_2.0: A general-purpose parallel molecular dynamics simulation package. J. Mol. Graphics, 14, 136 (1996).

[30] G. Lusvardi, G. Malavasi, L. Menabue, M.C. Menziani, A. Pedone, U. Segre. A computational tool for the prediction of crystalline phases obtained from controlled crystallization of glasses. J. Phys. Chem. B, 109, 215886 (2005).

[31] J.C. Hurt, C.J. Phillips. Structural Role of Zinc Oxide in Glasses in the System Na,OZnO-SiO. J. Am. Ceram. Soc., 53, 269 (1971).

[32] T. Furukawa, W.B. White. Vibrational Spectra and Glass Structure. J. Non-Cryst. Solids, 38-39, 87 (1980).

[33] T. Dumas, L.J. Petiau. EXAFS Study of Titanium and Zinc Environments During Nucleation in a Cordierite Glass. J. Non-Cryst. Solids, 81, 201 (1986).) 
[34] A.B. Rosenthal, S.H. Garofalini. Molecular Dynamics Simulation of Amorphous Zinc Silicate. J. Non-Cryst. Solids, 87, 254 (1986).

[35] A.B. Rosenthal, S.H. Garofalini. Structural Role of Zinc Oxide in Silica and Soda-Silica Glasses. J. Am. Ceramic Soc., 70, 821 (1987).

[36] P.H. Gaskell. Structure, glass formation and properties. J. Non-Cryst. Solids. 192\&193, 9 (1995).

[37] G. Lusvardi, G. Malavasi, L. Menabue, M.C. Menziani. Zinc addition to sodiumcalcium-silicate bioglasses. Theoretical vs experimental results. In Advances in Science and Technology. (vol. 36, pp. 91-98). P. Vincenzini, A. Lami (Ed.), Techna srl, Faenza, Italy (2003).

[38] G. Lusvardi, G. Malavasi, L. Menabue, M.C. Menziani, U. Segre. CaO and ZnO in sodasilicate glasses: a molecular dynamic simulation study and experimental characterization. In Advances in Science and Technology. (vol. 42, pp. 127-134). P. Vincenzini, A. Lami (Ed.), Techna srl, Faenza, Italy (2004).

[39] G. Lusvardi, G. Malavasi, L. Menabue, M.C. Menziani, U. Segre, M.M. Carnasciali, A. Ubaldini. A combined experimental and computational to $\left(\mathrm{Na}_{2} \mathrm{O}\right)_{1-\mathrm{x}} \cdot \mathrm{CaO} \cdot(\mathrm{ZnO})_{\mathrm{x}} \cdot 2 \mathrm{SiO}_{2}$ glasses characterization. J. Non-Cryst. Solids, 345\&346, 710 (2004).

[40] G.D. Cody, B. Mysen, G. Saghi-Szabo, J.A. Tossel. Silicate-phospate interactions in silicate glasses and melts: I. A multinuclear $\left({ }^{27} \mathrm{Al},{ }^{29} \mathrm{Si},{ }^{31} \mathrm{P}\right)$ MAS NMR and ab initio chemical shielding $\left({ }^{31} \mathrm{P}\right)$ study of phosphorous speciation in silicate glasses. Geochimica et Cosmochimica Acta, 65(14), 2395 (2001).

[41] G.N. Greaves. EXAFS and the structure of glass. J. Non-Cryst. Solids, 71, 203 (1985).

[42] A.N. Cormack, J. Du. Molecular dynamics simulations of. soda-lime-silicate glasses. $J$. Non Cryst. Sol., 293-295, 283 (2001). 
[43] C. Leonelli, G. Lusvardi, M. Montorsi, M.C. Menziani, L. Menabue, P. Mustarelli, L. Linati. Influence of small additions of $\mathrm{Al}_{2} \mathrm{O}_{3}$ on the properties of the $\mathrm{Na}_{2} \mathrm{O}-3 \mathrm{SiO}_{2}$ glass. $J$. Phys. Chem. B, 101, 919 (2001).

[44] V.R. Mastelaro, E.D. Zanotto, N. Lequeux, R. Cortes. Relationship between short-range order and ease of nucleation in $\mathrm{Na}_{2} \mathrm{Ca}_{2} \mathrm{Si}_{3} \mathrm{O}_{9}, \mathrm{CaSiO}_{3}$ and $\mathrm{PbSiO}_{3}$ glasses. J. Non-Cryst. Solids, 262, 191 (2000).

[45] J. Schneider, V.R. Mastelaro, H. Panepucci, E.D. Zanotto. ${ }^{29}$ Si MAS-NMR studies of Qn structural units in metasilicate glasses and their nucleating ability. J. Non-Cryst. Solids, 273, 8 (2000).

[46] Inorganic Crystal Structure Database (ICSD), version 1.3.3; NIST, Gaithersburg, MD(USA), 2004.

[47] J.F. Stebbins in Structure, Dynamics and Properties of Silicate Melts, J.F. Stebbins, P.F. McMillan, D.B. Dingwell (eds.), Mineralogical Society of America, 1995, p. 191.

[48] T.M. Clark, P.J. Grandinetti, P. Florian, J.F. Stebbins. Correlated structural distributions in silica glass. Phys Rev. B, 70, 064202 (2004).

[49] G. Engelhardt, D. Michel. High-Resolution Solids State NMR of Silicate and Zeolites, Wiley\&Sons, Chichester (UK), 1987.

[50] N. Janes, E. Oldfield,. Prediction of silicon-29 NMR chemical shifts using a group electronegativity approach: applications to silicate and aluminosilicate structures. $J$. Am. Chem. Soc., 107, 6769-6775 (1985).

[51] P. Gonzalez, J. Serra, S. Liste, S. Chiussi, B. León, M. Pérez-Amor. Raman spectroscopic study of bioactive silica based glasses. J. Non-Cryst. Solids, 320, 92 (2003).

[52] G. Lusvardi, G. Malavasi, L. Menabue, M.C. Menziani, A. Pedone, U. Segre. Density of multicomponet silica-based potential bioglasses: quantitative structure-property relationships (QSPR) analysis. J. Eur. Ceram. Soc., (2006) in press, doi:10.1016/j.jeurceramsoc.2006.04.067 
[53] A.N. Cormack, Y. Cao. Molecular dynamics simulation of silicate glasses. Mol. Eng., 6, 183 (1996).

[54] J.F. Shackelford. Gas solubility is glasses - principles and structural. J. Non-Cryst. Solids, 253, 231 (1999).

[55] S. Putta, S.N. Nasser. Molecularly-Based Numerical Evaluation of Free Volume in Amorphous Polymers. Materials Science and Engineering A, 317, 70 (2001).

[56] Volf, M.B. Mathematical approach to Glass; Glass Science and Technology, Vol. 9, , ed. Elsevier, Prague 1988 and references therein.

[57] J. Klinowski, S. Ramdas, J.M. Thomas, C.A. Fyfe, J. S. Hartman, J. Chem. Soc., Faraday Trans. 1982, 78, 1025 
TABLE 1. Molar composition of the studied glasses. (KZ: $2 \mathrm{SiO}_{2} \cdot \mathrm{Na}_{2} \mathrm{O} \cdot \mathrm{CaO} \cdot \mathrm{xZnO}$; KSZ: (2-y) $\mathrm{SiO}_{2} \cdot \mathrm{Na}_{2} \mathrm{O} \cdot \mathrm{CaO} \cdot y Z n O ; ~ K N Z: ~ 2 \mathrm{SiO}_{2} \cdot(1-\mathrm{z}) \mathrm{Na}_{2} \mathrm{O} \cdot \mathrm{CaO} \cdot \mathrm{zZnO} ; \mathbf{H Z}, \mathbf{H P 5 Z}, \mathbf{H P 6 . 5 Z}$ and HP8: (2-p) $\left.\mathrm{SiO}_{2} \cdot 1.1 \mathrm{Na}_{2} \mathrm{O} \cdot \mathrm{CaO} \cdot \mathrm{pP}_{2} \mathrm{O}_{5} \cdot \mathrm{XZnO}\right)$

\begin{tabular}{|c|c|c|c|c|c|c|}
\hline Series & & $\mathrm{SiO}_{2}$ & $\mathrm{Na}_{2} \mathrm{O}$ & $\mathrm{CaO}$ & $\mathrm{P}_{2} \mathrm{O}_{5}$ & $\mathrm{ZnO}$ \\
\hline \multirow{4}{*}{2} & $\mathrm{x}=0$ & 50.0 & 25.0 & 25.0 & I & I \\
\hline & $\mathrm{x}=0.17$ & 47.0 & 24.2 & 24.6 & l & 4.2 \\
\hline & $x=0.34$ & 45.4 & 23.4 & 23.3 & I & 8.0 \\
\hline & $x=0.68$ & 42.6 & 21.4 & 21.5 & I & 14.5 \\
\hline \multirow{3}{*}{$\begin{array}{l}N \\
\hat{n} \\
v\end{array}$} & $y=0.15$ & 45.7 & 25.3 & 25.3 & I & 3.7 \\
\hline & $y=0.19$ & 44.5 & 25.4 & 25.4 & I & 4.7 \\
\hline & $y=0.23^{a}$ & 43.5 & 25.4 & 25.4 & l & 5.7 \\
\hline \multirow{3}{*}{$\underset{\Sigma}{N}$} & $\mathrm{z}=0.20$ & 50.0 & 20.0 & 25.0 & I & 5.0 \\
\hline & $\mathrm{z}=0.60$ & 50.0 & 10.0 & 25.0 & l & 10.0 \\
\hline & $\mathrm{z}=1.00$ & 50.0 & I & 25.0 & I & 25.0 \\
\hline \multirow{4}{*}{ 坴 } & $\mathrm{x}=0 \mathrm{p}=0.10$ & 46.2 & 24.3 & 26.9 & 2.6 & I \\
\hline & $\mathrm{x}=0.16 \mathrm{p}=0.10$ & 44.4 & 23.4 & 25.9 & 2.5 & 3.8 \\
\hline & $\mathrm{x}=0.32 \mathrm{p}=0.10$ & 42.5 & 22.5 & 24.8 & 2.4 & 7.8 \\
\hline & $x=0.78 p=0.10$ & 38.8 & 20.5 & 22.6 & 2.2 & 15.9 \\
\hline \multirow{4}{*}{$\stackrel{N}{\hat{I}}$} & $\mathrm{x}=0 \mathrm{p}=0.20$ & 43.7 & 24.4 & 26.9 & 5.0 & I \\
\hline & $\mathrm{x}=0.16 \mathrm{p}=0.20$ & 42.1 & 23.4 & 25.9 & 4.7 & 3.9 \\
\hline & $\mathrm{x}=0.36 \mathrm{p}=0.20$ & 40.2 & 22.4 & 24.8 & 4.6 & 8.0 \\
\hline & $\mathrm{x}=0.96 \mathrm{p}=0.20$ & 35.7 & 19.9 & 21.9 & 4.1 & 18.5 \\
\hline \multirow{4}{*}{$\begin{array}{l}N \\
n \\
0 \\
0\end{array}$} & $\mathrm{x}=0 \mathrm{p}=0.26$ & 42.2 & 24.3 & 26.9 & 6.5 & 1 \\
\hline & $\mathrm{x}=0.17 \mathrm{p}=0.26$ & 40.5 & 23.4 & 25.8 & 6.2 & 4.0 \\
\hline & $\mathrm{x}=0.36 \mathrm{p}=0.26$ & 38.8 & 22.4 & 24.7 & 6.0 & 8.1 \\
\hline & $\mathrm{x}=0.58 \mathrm{p}=0.26$ & 37.0 & 21.3 & 23.6 & 5.7 & 12.3 \\
\hline$\stackrel{\infty}{\mid}$ & $\mathrm{x}=0 \mathrm{p}=0.36^{\mathrm{a}}$ & 40.0 & 24.4 & 26.9 & 8.7 & 1 \\
\hline
\end{tabular}


TABLE 2. Interatomic pair potential parameters for the Buckingham function with full ionic charges.

\begin{tabular}{rccc}
\hline \multicolumn{1}{c}{ Pair } & $A_{i j}(\mathrm{eV})$ & $C_{i j}\left(\mathrm{eV}^{*} \AA^{-6}\right)$ & $\rho(\AA)$ \\
\hline $\mathrm{Si}^{+4}-\mathrm{O}^{-2}$ & 1036.89 & 0 & 0.3259 \\
$\mathrm{P}^{+5}-\mathrm{O}^{-2}$ & 1273.42 & 0 & 0.3227 \\
$\mathrm{Zn}^{+2}-\mathrm{O}^{-2}$ & 700.3 & 0 & 0.3372 \\
$\mathrm{Ca}^{+2}-\mathrm{O}^{-2}$ & 1228.9 & 0 & 0.3118 \\
$\mathrm{Na}^{+1}-\mathrm{O}^{-2}$ & 1226.8 & 0 & 0.3065 \\
$\mathrm{O}^{-2}-\mathrm{O}^{-2}$ & 3116130.6 & 61.3916 & 0.1515 \\
\hline
\end{tabular}


TABLE 3. Potential parameters derived from binary oxides. $\mathrm{Li}, \mathrm{Na}$ and $\mathrm{K}$ were derived from silicates of general formula $\mathrm{M}_{2} \mathrm{Si}_{2} \mathrm{O}_{5}$

\begin{tabular}{|c|c|c|c|c|}
\hline Pair & $\mathrm{D}_{\mathrm{ij}} / \mathrm{eV}$ & $\mathrm{a}_{\mathrm{ij}} / \AA^{-2}$ & $\mathrm{r}_{0} / \AA$ & $\mathrm{C}_{\mathrm{ij}} / \mathrm{eV} \AA^{12}$ \\
\hline $\mathrm{Li}^{0.6}-\mathrm{O}^{-1.2}$ & 0.001114 & 3.429506 & 2.681360 & 1.0 \\
\hline $\mathrm{Na}^{0.6}-\mathrm{O}^{-1.2}$ & 0.023363 & 1.763867 & 3.006315 & 5.0 \\
\hline $\mathrm{K}^{0.6}-\mathrm{O}^{-1.2}$ & 0.011612 & 2.062605 & 3.305308 & 5.0 \\
\hline $\mathrm{Be}^{1.2}-\mathrm{O}^{-1.2}$ & 0.239919 & 2.527420 & 1.815405 & 1.0 \\
\hline $\mathrm{Mg}^{1.2}-\mathrm{O}^{-1.2}$ & 0.038908 & 2.281000 & 2.586153 & 5.0 \\
\hline $\mathrm{Ca}^{1.2}-\mathrm{O}^{-1.2}$ & 0.030211 & 2.241334 & 2.923245 & 5.0 \\
\hline $\mathrm{Sr}^{1.2}-\mathrm{O}^{-1.2}$ & 0.019623 & 1.886000 & 3.328330 & 3.0 \\
\hline $\mathrm{Ba}^{1.2}-\mathrm{O}^{-1.2}$ & 0.065011 & 1.547596 & 3.393410 & 5.0 \\
\hline $\mathrm{Sc}^{1.8}-\mathrm{O}^{-1.2}$ & 0.000333 & 3.144445 & 3.200000 & 2.6 \\
\hline $\mathrm{Ti}^{2.4}-\mathrm{O}^{-1.2}$ & 0.024235 & 2.254703 & 2.708943 & 1.0 \\
\hline $\mathrm{Zr}^{2.4}-\mathrm{O}^{-1.2}$ & 0.206237 & 2.479675 & 2.436997 & 1.0 \\
\hline $\mathrm{Cr}^{1.8}-\mathrm{O}^{-1.2}$ & 0.399561 & 1.785079 & 2.340810 & 1.0 \\
\hline $\mathrm{Mn}^{1.2}-\mathrm{O}^{-1.2}$ & 0.029658 & 1.997543 & 2.852075 & 3.0 \\
\hline $\mathrm{Fe}^{1.2}-\mathrm{O}^{-1.2}$ & 0.078171 & 1.822638 & 2.658163 & 2.0 \\
\hline $\mathrm{Fe}^{1.8}-\mathrm{O}^{-1.2}$ & 0.418981 & 1.620376 & 2.382183 & 2.0 \\
\hline $\mathrm{Co}^{1.2}-\mathrm{O}^{-1.2}$ & 0.012958 & 2.361272 & 2.756282 & 3.0 \\
\hline $\mathrm{Ni}^{1.2}-\mathrm{O}^{-1.2}$ & 0.029356 & 2.679137 & 2.500754 & 3.0 \\
\hline $\mathrm{Cu}^{0.6}-\mathrm{O}^{-1.2}$ & 0.090720 & 3.802168 & 2.055405 & 1.0 \\
\hline $\mathrm{Ag}^{0.6}-\mathrm{O}^{-1.2}$ & 0.088423 & 3.439162 & 2.265956 & 1.0 \\
\hline $\mathrm{Zn}^{1.2}-\mathrm{O}^{-1.2}$ & 0.001221 & 3.150679 & 2.851850 & 1.0 \\
\hline $\mathrm{Al}^{1.8}-\mathrm{O}^{-1.2}$ & 0.361581 & 1.900442 & 2.164818 & 0.9 \\
\hline $\mathrm{Si}^{2.4}-\mathrm{O}^{-1.2}$ & 0.340554 & 2.006700 & 2.100000 & 1.0 \\
\hline $\mathrm{Ge}^{2.4}-\mathrm{O}^{-1.2}$ & 0.158118 & 2.294230 & 2.261313 & 5.0 \\
\hline $\mathrm{Sn}^{2.4}-\mathrm{O}^{-1.2}$ & 0.079400 & 2.156770 & 2.633076 & 3.0 \\
\hline $\mathrm{P}^{3.0}-\mathrm{O}^{-1.2}$ & 0.831326 & 2.585833 & 1.800790 & 1.0 \\
\hline $\mathrm{Nd}^{1.8}-\mathrm{O}^{-1.2}$ & 0.014580 & 1.825100 & 3.398717 & 3.0 \\
\hline $\mathrm{Gd}^{1.8}-\mathrm{O}^{-1.2}$ & 0.000132 & 2.013000 & 4.351589 & 3.0 \\
\hline $\mathrm{Er}^{1.8}-\mathrm{O}^{-1.2}$ & 0.040448 & 2.294078 & 2.837722 & 3.0 \\
\hline $\mathrm{O}^{-1.2}-\mathrm{O}^{-1.2}$ & 0.042395 & 1.379316 & 3.618701 & $22.0^{*}$ \\
\hline
\end{tabular}

* The term $\mathrm{D} / \mathrm{r}^{12}$ is needed only in MD simulations and in free energy calculation at high temperature and pressure. In fact, the $\mathrm{D}_{\mathrm{O}-\mathrm{O}}$ term can range between 22 and $100 \mathrm{eV} \AA^{12}$ without altering the results of free-energy minimization at room temperature. 
Table 4. Crystal phases, relative intensities $\left(\mathrm{I} / \mathrm{I}_{0}\right)$ of the principal peaks identified by XRD analysis, and average similarity index $(\bar{\Delta}(\boldsymbol{r}))$ computed for the glasses studied.

\begin{tabular}{cccc}
\hline \multirow{2}{*}{ Glass } & Crystal phases & $\begin{array}{c}\text { Relative } \\
\text { intensities }\left(\mathrm{I} / \mathrm{I}_{0} \%\right)\end{array}$ & $\begin{array}{c}\text { Average similarity index } \\
\end{array}$ \\
\hline $\mathrm{HZ} \mathrm{x=0}$ & $\mathrm{Na}_{2} \mathrm{CaSi}_{2} \mathrm{O}_{6}$ & 100 & 0.08 \\
\hline \multirow{2}{*}{$\mathrm{HP6.5Z} \mathrm{x=0}$} & $\mathrm{Na}_{2} \mathrm{CaSi}_{2} \mathrm{O}_{6}$ & 100 & 0.16 \\
& $\beta-\mathrm{NaCaPO}_{4}$ & 65 & 0.57 \\
\hline \multirow{2}{*}{$\mathrm{HP}^{*}$} & $\beta-\mathrm{NaCaPO}_{4}$ & 100 & 0.54 \\
& $\mathrm{Na}_{2} \mathrm{CaSi}_{2} \mathrm{O}_{6}$ & 72 & 0.31 \\
\hline \multirow{2}{*}{$\mathrm{HZ} \mathrm{x=0.78}$} & $\mathrm{Na}_{4} \mathrm{Zn}_{2} \mathrm{Si}_{3} \mathrm{O}_{10}$ & 100 & 0.64 \\
& $\mathrm{Na}_{2} \mathrm{CaSi}_{2} \mathrm{O}_{6}$ & 14 & 0.29 \\
& $\mathrm{Zn}_{2} \mathrm{SiO}_{4}$ & 7 & 3.72 \\
\hline \multirow{2}{*}{${\mathrm{KSZ} \mathrm{y}=0.23^{*}}^{*}$} & $\mathrm{Na}_{2} \mathrm{ZnSiO}_{4}$ & 70 & 0.80 \\
& $\mathrm{Na}_{4} \mathrm{Zn}_{2} \mathrm{Si}_{3} \mathrm{O}_{10}$ & 70 & 1.65 \\
& $\mathrm{Na}_{2} \mathrm{CaSi}_{2} \mathrm{O}_{6}$ & 100 & 0.11 \\
\hline
\end{tabular}

*glass partially crystallized 


\section{Figure Captions:}

Figure 1: Workflow of molecular dynamic simulations performed and result analysis.

Figure 2: Snapshot of the simulated (a) $\mathrm{KZ} x=0.68$ and (c) $\mathrm{HZ} \mathrm{x}=0$ glass structures. (a) shows the interconnection of $\mathrm{SiO}_{4}$ and $\mathrm{ZnO}_{4}$ tetrahedra and related bond distance and angles compared with the crystal phase $\mathrm{Na}_{2} \mathrm{ZnSiO}_{4}$ (b); (c) shows the isolated $\mathrm{PO}_{4}$ tetrahedra and related bond distance and angles compared with the crystal phase $\beta-\mathrm{NaCaPO}_{4}(\mathrm{~d})$. ( $\mathrm{Si}$ is represented in yellow, $\mathrm{Zn}$ in violet, $\mathrm{P}$ in green, $\mathrm{O}$ in red, $\mathrm{Na}$ in pink and $\mathrm{Ca}$ in blue).

Figure 3: (a)-Correlation between the structural descriptors $\mathrm{N}^{\circ} \mathrm{X}-\mathrm{O}-\mathrm{X} / \mathrm{Otot}$ and the total leaching $\Sigma \% \mathrm{X}_{\mathrm{i}}$, sum of \% leaching of each constituent of HZ and HP5Z glass series; (b)-Correlation between structural descriptors $\mathrm{N}^{\circ}$ X-O-X/Otot and experimental density measured for the glasses studied. Glasses belonging to the test set are represented by a triangle. 


\section{Page 33 of 35}

1

2 Figure 1

3

Figure 1

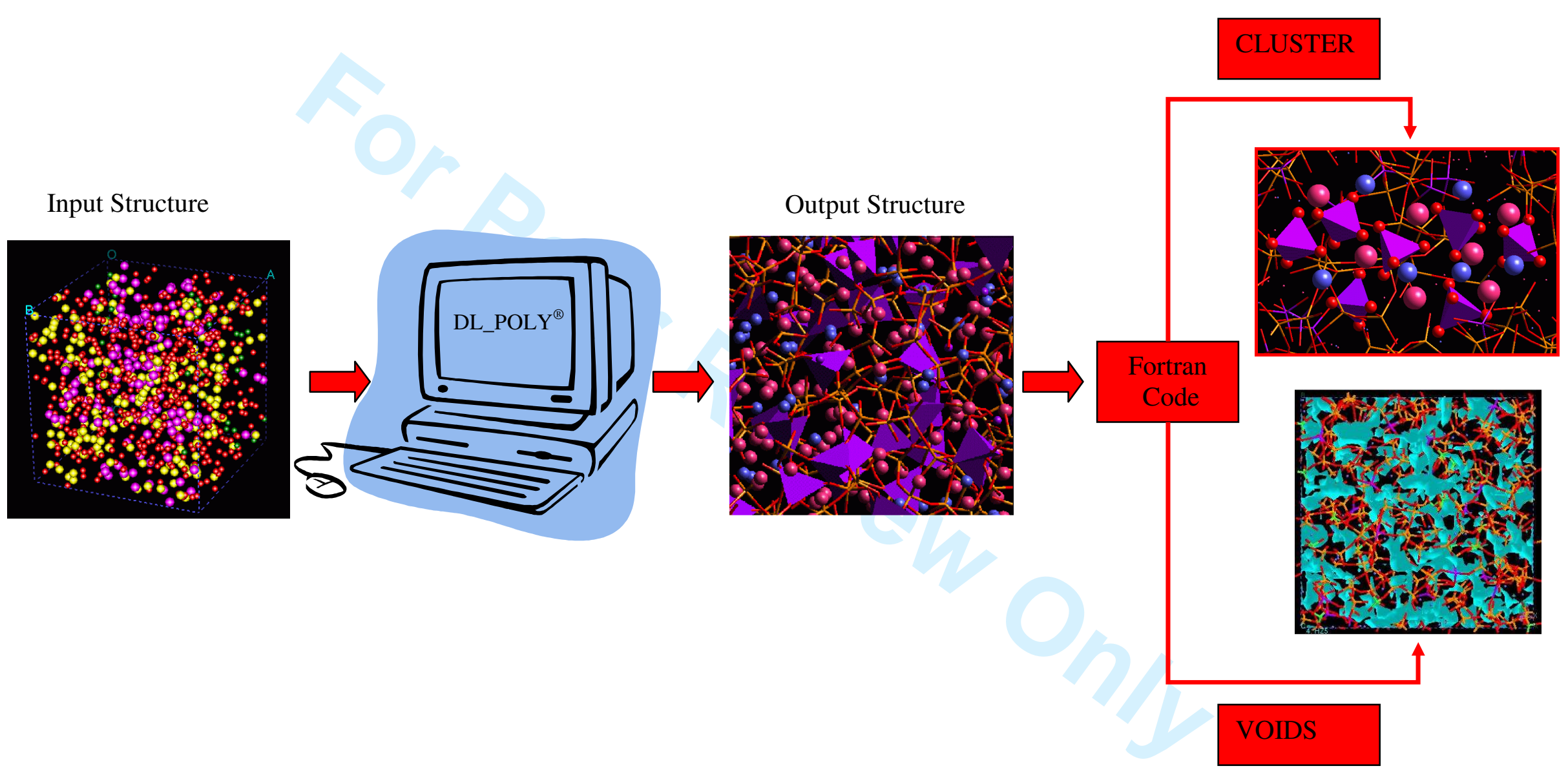


Figure 2

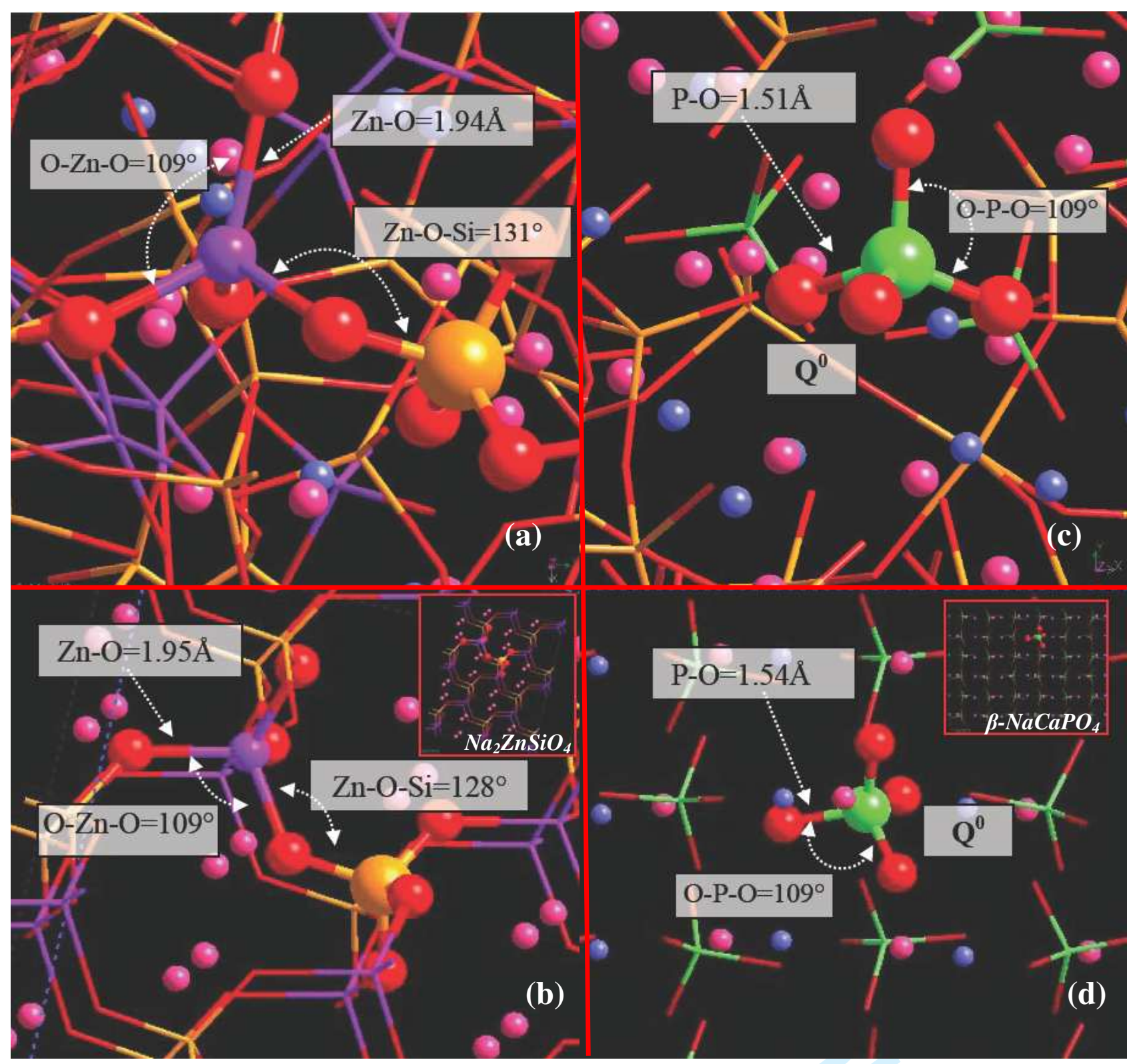




\section{Page 35 of 35}

Figure 3

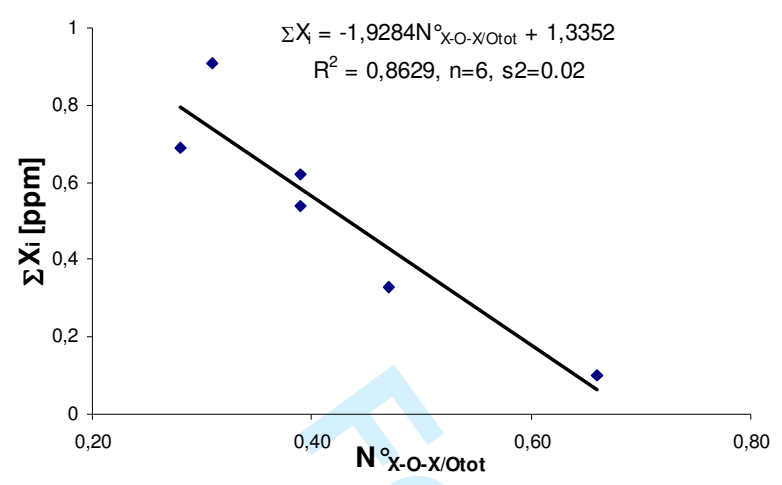

(a)

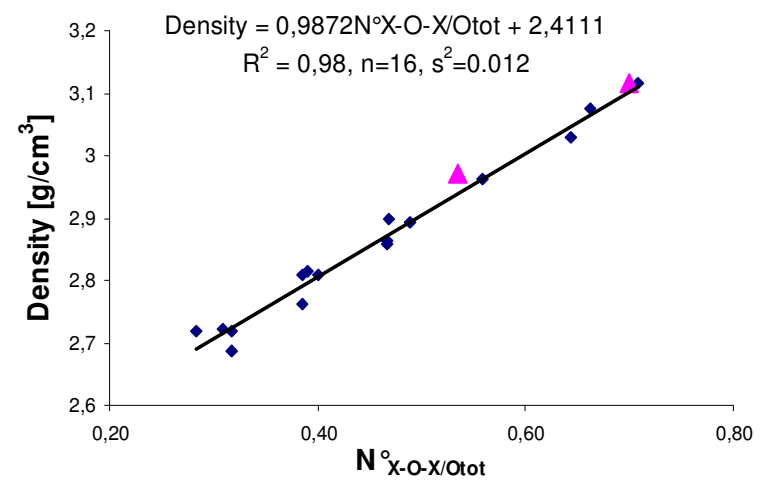

(b) 